\title{
Transformation Mechanism of $\left(\gamma+\gamma^{\prime}\right)$ and the Effect of Cooling Rate on the Final Solidification of U720Li Alloy
}

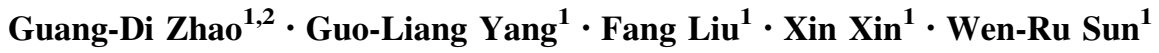

Received: 9 October 2016/Revised: 16 November 2016/Published online: 20 March 2017

(C) The Chinese Society for Metals and Springer-Verlag Berlin Heidelberg 2017

\begin{abstract}
The transformation mechanism of $\left(\gamma+\gamma^{\prime}\right)$ was studied by analyzing the microstructure and elemental distribution of the $\mathrm{U} 720 \mathrm{Li}$ samples heated at $1250{ }^{\circ} \mathrm{C}$ and cooled at the rates in the range of $1-100{ }^{\circ} \mathrm{C} / \mathrm{s}$. Although the $\left(\gamma+\gamma^{\prime}\right)$ is deemed to be formed by a eutectic reaction and has been called eutectic $\left(\gamma+\gamma^{\prime}\right)$, it was found in the present study that the $\left(\gamma+\gamma^{\prime}\right)$ precipitation begins with a peritectic reaction of $(\mathrm{L}+\gamma) \rightarrow \gamma^{\prime}$, and develops by the eutectic reaction of $\mathrm{L} \rightarrow\left(\gamma+\gamma^{\prime}\right)$. The energy for the $\gamma^{\prime}$ nucleation is low because the interfacial energy for the $\gamma / \gamma^{\prime}$ interface is about one-tenth of the solid/liquid interface, and hence, the nucleation rate is high and the fine structure of $\left(\gamma+\gamma^{\prime}\right)$ is formed at the initial precipitation stage. The $\gamma$ and $\gamma^{\prime}$ in $\left(\gamma+\gamma^{\prime}\right)$ tend to grow into a lamellar structure because it is difficult for them to nucleate directly from the residual liquids, and hence, the $\gamma^{\prime}$ precipitates naturally tend to grow divergently direction of the regions rich in $\mathrm{Al}$ and $\mathrm{Ti}$, forming a fan-like structure of the $\left(\gamma+\gamma^{\prime}\right)$. As a result, the $\gamma^{\prime}$ precipitates will coarsen finally because the space between them is enlarged. The solidification of the final residual liquids is a diffusion dependent process. When cooled at a higher rate, a higher degree of super cooling is reached and finally the solidification is finished by the pseudoeutectic reaction of $\mathrm{L} \rightarrow(\gamma+$ boride $)$ and $\mathrm{L} \rightarrow(\gamma+\eta)$, which can absorb $\mathrm{Zr}$ and $\mathrm{B}$. When cooled at a rate low enough, most of the residual liquids are consumed by the $\left(\gamma+\gamma^{\prime}\right)$ growth due to the sufficient diffusion, and the boride and $\mathrm{Zr}$ bearing phase are precipitated at a quasi-equilibrium state. Under this condition, Ti is depleted at the $\left(\gamma+\gamma^{\prime}\right)$ growth front. However, the $\eta-\mathrm{Ni}_{3} \mathrm{Ti}$ phase is formed there occasionally due to the boride precipitation, because the compositions of the two phases are complementary.
\end{abstract}

KEY WORDS: U720Li; $\left(\gamma+\gamma^{\prime}\right)$ formation mechanism; Cooling rate; Solidification

Available online at http://link.springer.com/journal/40195.

Wen-Ru Sun

wrsun@imr.ac.cn

Guang-Di Zhao

gdzhao12s@imr.ac.cn

1 Institute of Metal Research, Chinese Academy of Sciences, Shenyang 110016, China

2 School of Materials Science and Engineering, University of Science and Technology of China, Hefei 230026, China

\section{Introduction}

Nickel-based superalloys are extensively used as hightemperature components of gas turbines due to their excellent strength, and creep, fatigue and corrosion resistance at elevated temperatures $[1,2]$. The excellent hightemperature strength is mostly derived from the precipitation of ordered and coherent $\gamma^{\prime}\left(\mathrm{Ni}_{3} \mathrm{Al}\right)$ phase from the solid solution matrix [3]. The U720Li, with the higher $\mathrm{Al}$ and $\mathrm{Ti}$ $(\mathrm{Al}+\mathrm{Ti} \approx 7.5 \mathrm{wt} \%)$ additions, is a relatively new highstrength Ni-based superalloy for turbine disk application. 
However, the high level of $(\mathrm{Al}+\mathrm{Ti})$ addition naturally causes the severe segregation and the heavy precipitation of eutectic $\left(\gamma+\gamma^{\prime}\right)$ in the interdendritic area [4]. It is well known that the eutectic $\left(\gamma+\gamma^{\prime}\right)$ should be removed by homogenization at elevated temperature $[5,6]$, because it reduces the $\gamma^{\prime}$ precipitation and the mechanical properties, and lowers the processing abilities such as cogging.

The $\left(\gamma+\gamma^{\prime}\right)$ is harmful and should be controlled strictly during solidification, and the transformation mechanism is no doubt the grounding for controlling its precipitation. The transformation of $\left(\gamma+\gamma^{\prime}\right)$ is traditionally believed to be a eutectic reaction and the $\left(\gamma+\gamma^{\prime}\right)$ is routinely called the eutectic $\left(\gamma+\gamma^{\prime}\right)$. However, there is different viewpoint on the $\left(\gamma+\gamma^{\prime}\right)$ precipitation. Hilpert et al. [7] established the Al-Ni phase diagram and pointed out that the $\left(\gamma+\gamma^{\prime}\right)$ was formed by a peritectic reaction. The $\left(\gamma+\gamma^{\prime}\right)$ is composed of mainly two parts: one part appears like a 'cap' consisting of coarse $\gamma^{\prime}$ particles and the $\gamma$ phase between them, and the other part looks like a network consisting of fine $\gamma^{\prime}$ and $\gamma$ phase mixed together uniformly. D'Souza and Dong [8] deemed that the $\gamma^{\prime}$ phase nucleates from primary $\gamma$ dendrites at the solid/liquid interface via a peritectic reaction of $(L+\gamma) \rightarrow \gamma^{\prime}$. Then the peritectic reaction terminates, and the $\gamma^{\prime}$ phase grows via the reaction of $\left(\mathrm{L} \rightarrow \gamma^{\prime}\right)$ at the expense of the remaining liquid, forming the cap-like part with coarse $\gamma^{\prime}$ particles. Finally, the fine lamellar $\gamma-\gamma^{\prime}$ eutectic is formed in the segregated terminal liquid between the abutting coarse $\gamma^{\prime}$ particles by a terminal eutectic reaction shown as $\mathrm{L} \rightarrow\left(\gamma+\gamma^{\prime}\right)$. However, the above studies lack the direct experimental support. Thus, the transformation mechanism of the $\left(\gamma+\gamma^{\prime}\right)$ needs further investigation to provide theoretical guidance for controlling this phase properly.

It is well known that the cooling rate has a significant influence on the solidification process and microstructure of Ni-based superalloys [1,9-11], and the evolution of microstructures with respect to the cooling rate is closely related to the precipitation behavior of the phases. Therefore, the solidification under different cooling rates might reflect some characteristic of $\left(\gamma+\gamma^{\prime}\right)$ precipitation arising from its formation mechanism. In the present study, the precipitation behavior of U720Li alloy under different cooling rates was investigated, mainly focusing on the precipitation mechanism of $\left(\gamma+\gamma^{\prime}\right)$ and its effect on the precipitation of the minor phases including borides, $\eta$ $\mathrm{Ni}_{3} \mathrm{Ti}$ and the $\mathrm{Zr}$-bearing phase.

\section{Experimental}

The U720Li ingot weighted $6 \mathrm{~kg}$ was produced by vacuum induction melting, and the composition of the ingot was analyzed by inductively coupled plasma-atomic emission spectrometry (ICP-AES) to be as $\mathrm{Al} 2.42$, Ti 5.06, Co 14.99, W 1.24, Mo 3.09, Cr 15.66, C 0.010, B 0.014, Zr 0.035 and balance $\mathrm{Ni}$ (wt\%). As-cast samples of $10 \mathrm{~mm} \times 10 \mathrm{~mm} \times 10 \mathrm{~mm}$ were cut from half radius of the ingot by using an electron discharge machine (EDM) for microstructure observation. Continuous cooling test was designed to study the effect of the linear, fixed cooling rates on the final precipitation behavior of U720Li. The cooling tests were carried out using L78RITA quenching transformation measuring apparatus (LINSEIS, Germany). Samples used in the tests were also taken from half radius of the ingot. The geometry of the samples was cylindrical, with height of $8 \mathrm{~mm}$ and diameter of $6 \mathrm{~mm}$. Figure 1 shows the recorded temperature-time profiles of U720Li samples. The samples were heated up to $1250{ }^{\circ} \mathrm{C}$ with a heating rate of $10{ }^{\circ} \mathrm{C} / \mathrm{s}$, held at $1250{ }^{\circ} \mathrm{C}$ for $10 \mathrm{~min}$ to melt the $\left(\gamma+\gamma^{\prime}\right)$ in the interdendritic area and finally cooled to room temperature at $100,20,5$ and $1{ }^{\circ} \mathrm{C} / \mathrm{s}$, respectively. The holding temperature $\left(1250{ }^{\circ} \mathrm{C}\right)$ is higher than the $\left(\gamma+\gamma^{\prime}\right)$ precipitation temperature [5].

The as-cast samples and the cooled samples were polished using standard metallographic techniques and were subsequently etched electrolytically in a solution of $(13 \mathrm{ml}$ $\mathrm{H}_{3} \mathrm{PO}_{4}+42 \mathrm{ml} \mathrm{HNO}_{3}+45 \mathrm{ml} \mathrm{H}_{2} \mathrm{SO}_{4}$ ) under DC $6 \mathrm{~V}$ for 5-10 s. This etching agent is often used to dissolve the $\gamma$ matrix selectively to reveal the other phases, such as $\gamma^{\prime}$ and borides. The microstructures were analyzed by optical microscopy (OM) and scanning electron microscopy (SEM, JEOL 6340). The energy-dispersive spectrometry (EDS) attached to the SEM was utilized to examine the composition of the precipitates in the interdendritic region of the as-cast sample and liquid pools of the samples. At least five positions were examined for each phase. A Shimadzu EPMA-1610 electron probe was used to characterize the element distribution in the interdendritic region of

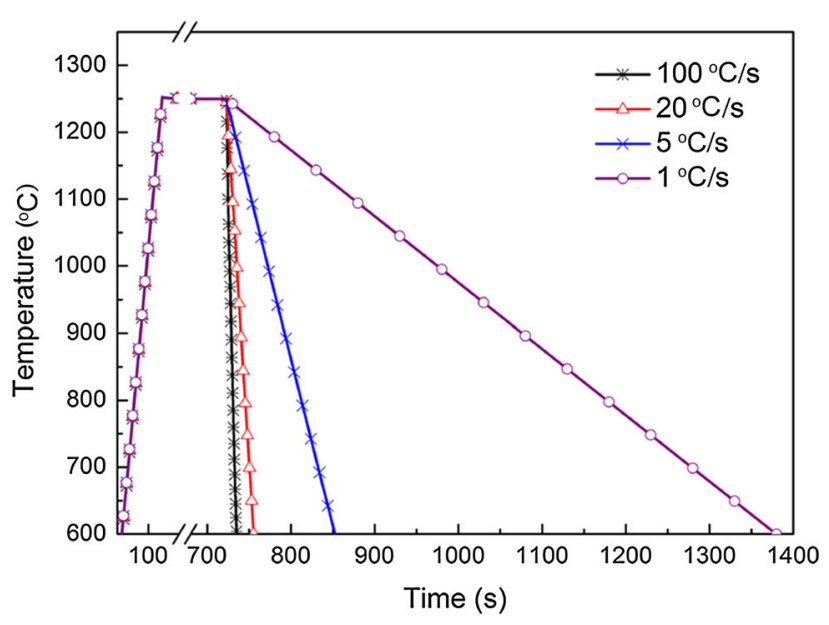

Fig. 1 Linear cooling profiles for the cooling test 
as-cast U720Li alloy. The specimens for transmission electron microscope (TEM) observation were prepared by conventional ion-thinning procedure. Thin foils were taken from the sample cooled at $100{ }^{\circ} \mathrm{C} / \mathrm{s}$. The TEM observations were performed on a Tecnai G2 20 electron microscope.

\section{Results}

\subsection{Microstructure and element distribution in as- cast state}

Figure 2 presents the microstructure of the as-cast U720Li alloy under optical microscope and SEM. The dendrite core appears with a dark color, and the interdendritic region appears with a bright color. The rosette-like $\left(\gamma+\gamma^{\prime}\right)$ formed at the final stage of solidification is located preferentially in the interdendritic region (Fig. 2a). The lathlike $\eta$ phase, irregular shaped borides and $\mathrm{Zr}$-bearing particles were occasionally found in front of the $\left(\gamma+\gamma^{\prime}\right)$ under SEM observation (Fig. 2b), which is consistent with our previous study [4]. Interestingly, these three minor phases were usually close to each other and the borides were always attached to the $\eta$ phases.

The element distribution of the interdendritic region is shown in Fig. 3. The $\left(\gamma+\gamma^{\prime}\right)$ are enriched in Ti, but depleted in $\mathrm{Co}, \mathrm{Cr}$ and Mo. Besides, the concentration of $\mathrm{Ti}$ increases gradually from the fine net-like part of the $\left(\gamma+\gamma^{\prime}\right)$ to the cap-like part with coarse $\gamma^{\prime}$ particles, which indicates that segregation even exists in different areas of the $\left(\gamma+\gamma^{\prime}\right)$, while the $\gamma^{\prime}$ forming element Al tends to be distributed uniformly between the $\left(\gamma+\gamma^{\prime}\right)$ and $\gamma$ dendrites, which indicates that the formation of $\left(\gamma+\gamma^{\prime}\right)$ mainly depends on the segregation of Ti. The borides are enriched in $\mathrm{B}, \mathrm{Cr}$ and $\mathrm{Mo}$, but extremely depleted in $\mathrm{Ti}, \mathrm{Al}$ and $\mathrm{Co}$.
The black particles are only enriched in $\mathrm{Zr}$ and are confirmed to be the Zr-bearing phase. However, there exists a line just in front of the $\left(\gamma+\gamma^{\prime}\right)$, which is depleted in Ti and $\mathrm{Al}$, but enriched in $\mathrm{Cr}$.

The in situ composition analysis by EDS (Table 1) suggests that the borides are mainly composed with Mo and $\mathrm{Cr}$, which is in agreement with the element distribution determined by EPMA and the previous reports [12-14]. The Zr-bearing particles are mainly composed with $\mathrm{Ni}$ and $\mathrm{Zr}$, which is consistent with the previous studies $[4,15]$. The $\eta$ phase is highly enriched in $\mathrm{Ni}$ and $\mathrm{Ti}$, and similar results have been reported in the literature [16]. Besides, $\mathrm{Zr}$ is also dissolved in the $\eta$ phase obviously, and similar results have been found in our previous study [4]. The coarse $\gamma^{\prime}$ at the cap-like part of the $\left(\gamma+\gamma^{\prime}\right)$ are composed with $\mathrm{Ni}, \mathrm{Ti}$ and $\mathrm{Al}$, and the concentration of $\mathrm{Ti}$ in the coarse $\gamma^{\prime}$ is lower than that in the $\eta$ phase.

\subsection{Effect of cooling rate on the solidification of residual liquids}

Figure 4 presents the dendritic structures of samples heated at $1250{ }^{\circ} \mathrm{C}$ and then cooled at different rates. Many large liquid pools were observed in interdendritic regions of the sample cooled at $100{ }^{\circ} \mathrm{C} / \mathrm{s}$ (Fig. 4a) and no original interdendritic precipitates remained, which indicated that the interdendritic precipitates, including $\left(\gamma+\gamma^{\prime}\right)$, were fully melted during the soaking at $1250{ }^{\circ} \mathrm{C}$. The size and volume fraction of liquid pools decreased obviously with the decrease in cooling rate. Besides, the edge of the liquid pools became coarser and some precipitates began to appear inside the liquid pools as the cooling rate decreased. When the cooling rate was decreased to $1{ }^{\circ} \mathrm{C} / \mathrm{s}$, the liquid pools disappeared and lots of $\left(\gamma+\gamma^{\prime}\right)$ were reprecipitated in the interdendritic region (Fig. 4d).
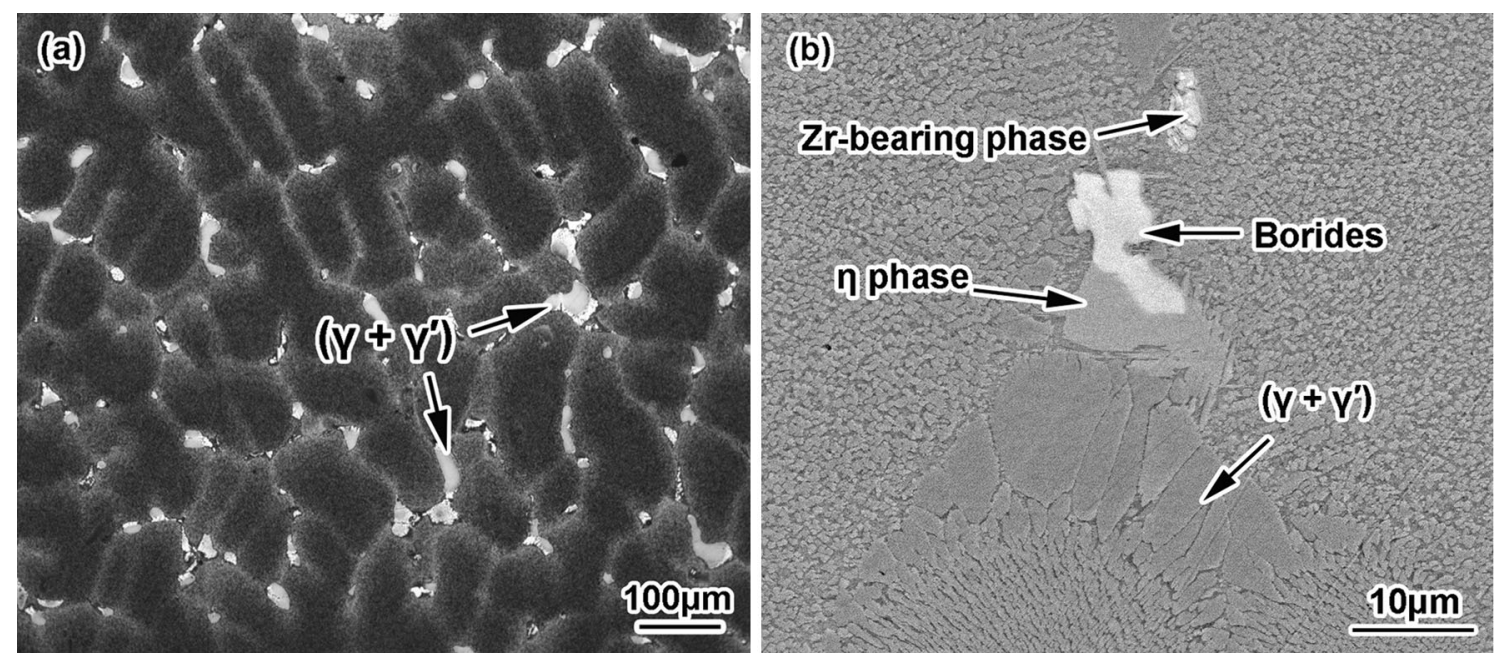

Fig. 2 As-cast microstructure of U720Li alloy: a dendritic structure, $\mathbf{b}$ the minor precipitates in front of the $\left(\gamma+\gamma^{\prime}\right)$ 


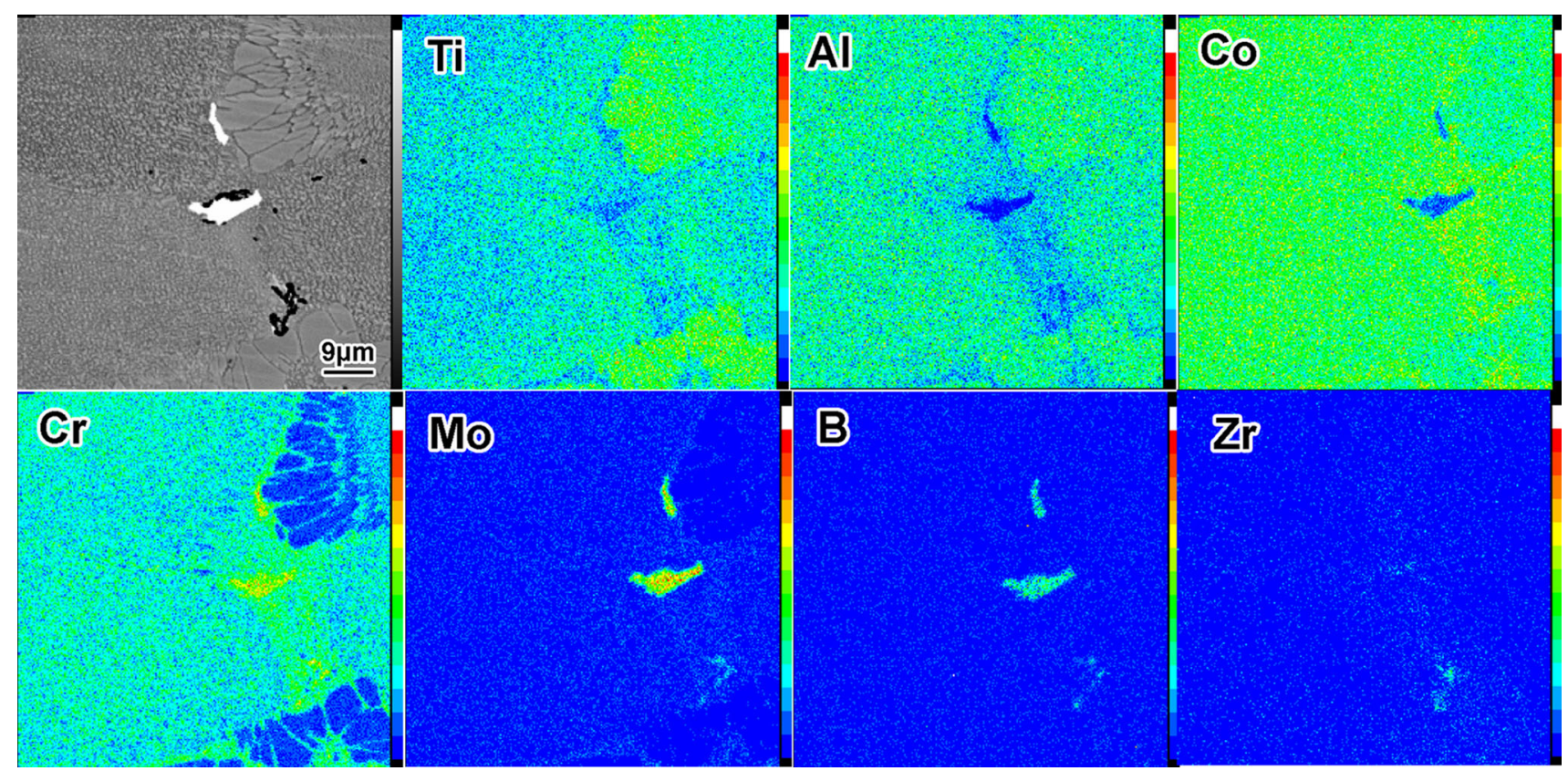

Fig. 3 Element distribution in the interdendritic region of the as-cast U720Li alloy

Table 1 Composition of the phases precipitated in the interdendritic area of the as-cast U720Li alloy (EDS results, wt\%)

\begin{tabular}{lllllrlll}
\hline Phase & $\mathrm{Al}$ & $\mathrm{Ti}$ & $\mathrm{Cr}$ & $\mathrm{Co}$ & $\mathrm{Ni}$ & $\mathrm{Mo}$ & $\mathrm{W}$ & $\mathrm{Zr}$ \\
\hline Borides & - & 4.25 & 32.27 & 2.12 & 2.93 & 53.16 & 5.26 & - \\
Zr-rich phase & 0.57 & 3.14 & 3.18 & 9.66 & 53.27 & - & - \\
$\eta$ phase & 2.17 & 15.06 & 4.00 & 11.96 & 63.09 & 0.68 & 0.91 & 2.13 \\
Coarse $\gamma^{\prime}$ & 3.84 & 13.65 & 4.46 & 10.08 & 65.12 & 1.12 & 0.82 & - \\
\hline
\end{tabular}

The morphologies of the liquid pools and resolidified microstructures in the liquid pools were observed further under SEM as shown in Fig. 5. When cooled at $100{ }^{\circ} \mathrm{C} / \mathrm{s}$, some fine lath-like precipitates and lots of honeycomb-like structures were observed inside the liquid pools as shown in Fig. 5a, and lots of divergent fine precipitates were precipitated at the edge of the liquid pools. The in situ composition analysis by EDS (Table 2) suggests that the composition of the fine lath-like precipitates is much similar with that of the $\eta$ phase in the as-cast microstructure (Table 1). The honeycomb-like structures are rich in Ti and $\mathrm{Zr}$ and should be the $\gamma$ phase frozen by the quick cooling. Figure 6 shows TEM bright-field image and the corresponding selected area diffraction patterns (SADPs) of a lath-like phase and the phase surrounding it in the sample cooled at $100{ }^{\circ} \mathrm{C} / \mathrm{s}$. The lath-like phase is enriched in $\mathrm{Ni}$ and Ti as measured by the TME-EDS, and it is determined accordingly to be the hexagonal $\eta-\mathrm{Ni}_{3} \mathrm{Ti}$ phase with lattice parameter of $a=0.513 \mathrm{~nm}$ and $c=0.822 \mathrm{~nm}$. The phase surrounding the $\eta-\mathrm{Ni}_{3}$ Ti phase is determined to be the facecentered cubic $\gamma$ phase with lattice parameter of $a=0.363 \mathrm{~nm}$. It is obvious that the fine lath-like precipitates and the honeycomb-like structures inside the liquid pools are just the $\eta-\mathrm{Ni}_{3} \mathrm{Ti}$ phase and $\gamma$ phase, respectively. The lath-like $\eta$ phase absorbs $\mathrm{Ti}$ and $\mathrm{Zr}$ and hence favors the precipitation of the honeycomb-like $\gamma$ phase. Figure $5 \mathrm{~b}$ show the enlarged image of the fine precipitates at the edge of the liquid pools marked in Fig. 5a in the rectangle. As shown in Table 2, the fine precipitates are highly enriched in $\mathrm{Ni}, \mathrm{Ti}$ and $\mathrm{Al}$ and are further confirmed to be $\left(\gamma+\gamma^{\prime}\right)$ by its SADP as shown in Fig. 7. When cooled at $20{ }^{\circ} \mathrm{C} / \mathrm{s}$, lots of lath-like $\eta$ phase and eutectic $(\gamma+$ boride $)$ were observed in the liquid pools as shown in Fig. 5c. The $\left(\gamma+\gamma^{\prime}\right)$ clusters grew obviously from the edge of the liquid pools. When cooled at $5{ }^{\circ} \mathrm{C} / \mathrm{s}$, the liquid pools became much smaller and less lath-like $\eta$ phase and eutectic $(\gamma+$ boride) were formed inside the liquid pools as shown in Fig. 5d. The $\left(\gamma+\gamma^{\prime}\right)$ has grown into the routinely observed rosette-like with fine $\gamma^{\prime}$ at the net-like part and coarse $\gamma^{\prime}$ particles at the cap-like part. When cooled at $1{ }^{\circ} \mathrm{C} / \mathrm{s}$, the liquid pools disappeared and the $\left(\gamma+\gamma^{\prime}\right)$ became much coarser and much less lath-like $\eta$ phase and borides were observed in front of the $\left(\gamma+\gamma^{\prime}\right)$ as shown in Fig. 5e, and the microstructure is similar with the 

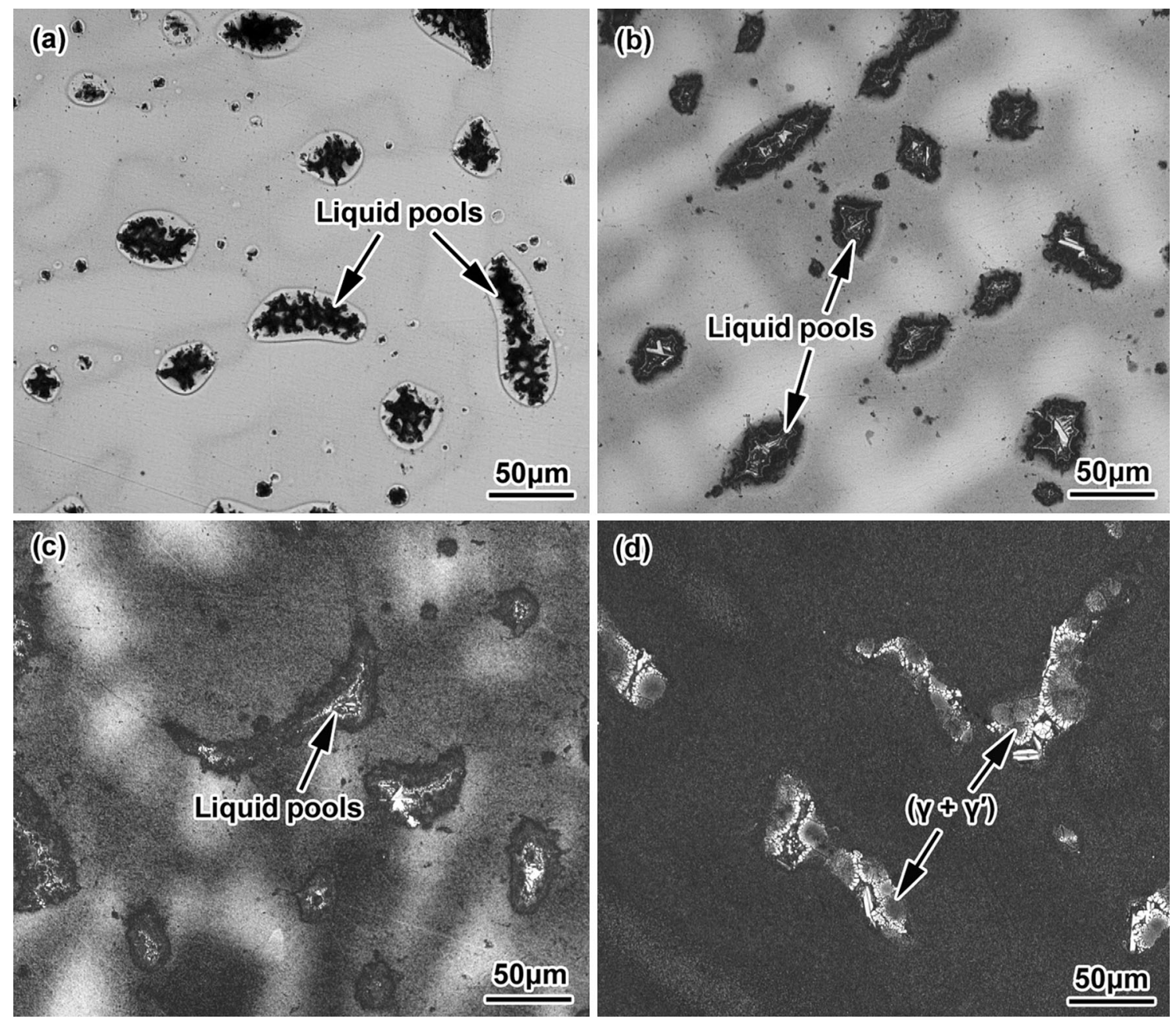

Fig. 4 Structures of the alloy soaked at $1250{ }^{\circ} \mathrm{C}$ for $10 \mathrm{~min}$ and then cooled to room temperature at different rates: a $100{ }^{\circ} \mathrm{C} / \mathrm{s}$, b $20{ }^{\circ} \mathrm{C} / \mathrm{s}$, c $5{ }^{\circ} \mathrm{C} / \mathrm{s}, \mathbf{d ~} 1{ }^{\circ} \mathrm{C} / \mathrm{s}$

as-cast microstructure of the alloy as shown in Fig. $2 \mathrm{~b}$. Overall, as the cooling rate decreased from 100 to $1{ }^{\circ} \mathrm{C} / \mathrm{s}$ the volume fraction of $\left(\gamma+\gamma^{\prime}\right)$ in the liquid pools was significantly increased. It is interesting that the volume fraction of $\eta$ phase and borides reached the maximum level when the cooling rate decreased from 100 to $20^{\circ} \mathrm{C} / \mathrm{s}$, and then decreased when the cooling rate was decreased from 20 to $1{ }^{\circ} \mathrm{C} / \mathrm{s}$. The minor $\mathrm{Zr}$-bearing phase was only occasionally found inside the liquid pools or in front of the $\left(\gamma+\gamma^{\prime}\right)$ and the cooling rate had no obvious influence on its precipitation.

\section{Discussion}

With the progress of the solidification, the $\left(\gamma+\gamma^{\prime}\right)$ is precipitated as a result of the segregation of $\mathrm{Ti}$ in the residual liquids, and the precipitation is traditionally deemed as a eutectic reaction ( $\left.\mathrm{L} \rightarrow \gamma+\gamma^{\prime}\right)$. If this is true, the liquid pools of the as-quenched sample should be occupied by a large amount of pseudo-eutectic $\left(\gamma+\gamma^{\prime}\right)$. However, the liquid pools were filled with honeycomb-like $\gamma$ phase and lath-like $\eta$ phase instead, and the $\left(\gamma+\gamma^{\prime}\right)$ was precipitated from the $\gamma$ matrix at the edge of the liquid pools as shown in Fig. 5a. This structure implies that the $\gamma^{\prime}$ might nucleate from primary $\gamma$ dendrites at the liquid $/ \gamma$ interface via a peritectic reaction of $(L+\gamma) \rightarrow \gamma^{\prime}$. The peritectic reaction might precede over the eutectic reaction for the $\left(\gamma+\gamma^{\prime}\right)$ precipitation, because the lattice misfit between $\gamma^{\prime}$ and $\gamma$ phases is small (usually of the order of $0.2 \%$ [17]) and the interfacial energy for the $\gamma / \gamma^{\prime}$ interface is about one-tenth of the solid/liquid interface energy, as has been suggested by the previous studies $[8,17]$.

Because the energy for the $\gamma^{\prime}$ nucleation from the $\gamma$ matrix via peritectic reaction is low, the $\gamma^{\prime}$ phase is densely formed at the $\gamma /$ liquid interface as shown in Fig. 5a, b. The fine $\gamma^{\prime}$ particles naturally tend to grow into the liquids due to the quick diffusion in it, which will lower the $\mathrm{Al}$ and $\mathrm{Ti}$ 

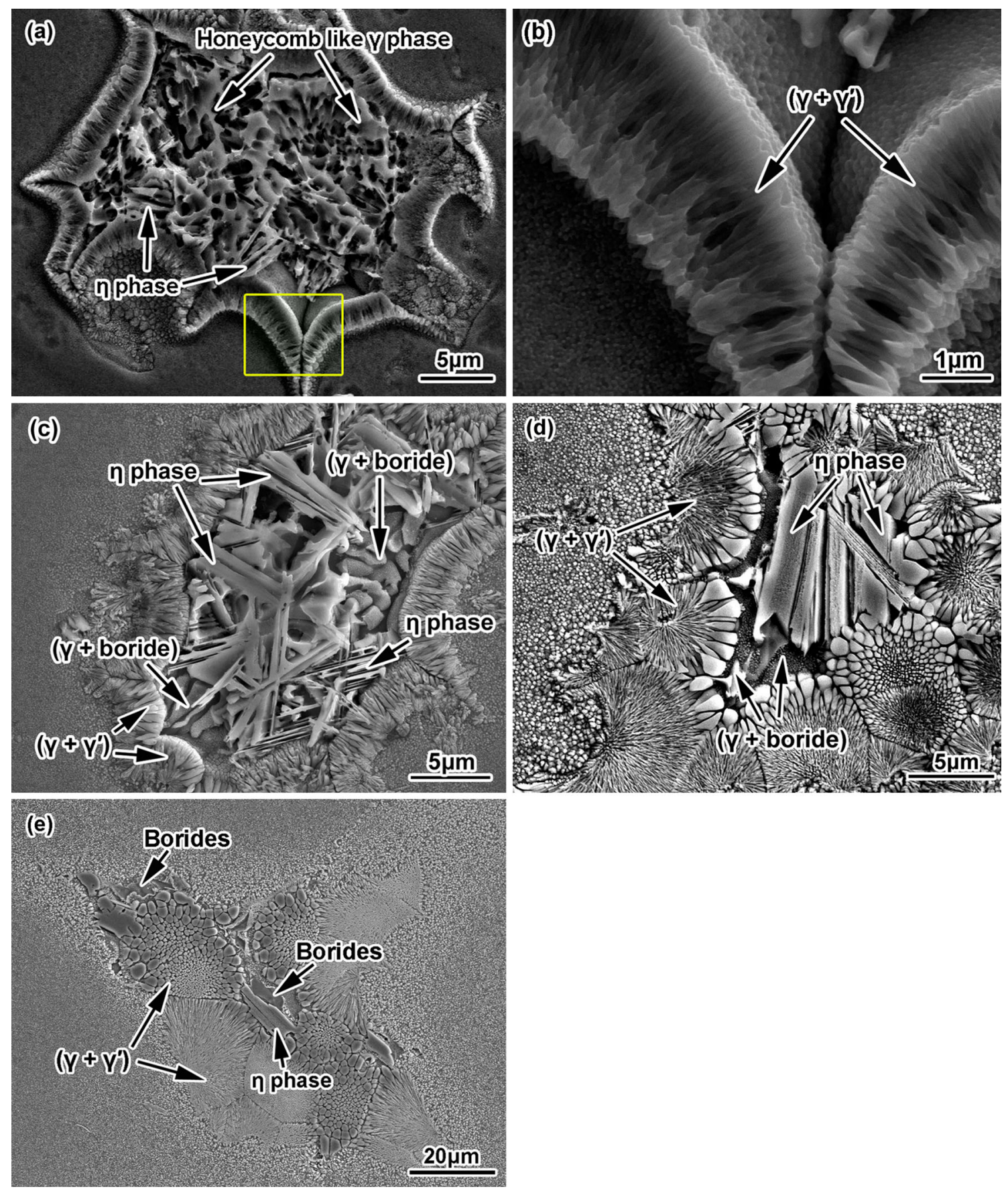

Fig. 5 Resolidified microstructures of liquid pools after soaking at $1250{ }^{\circ} \mathrm{C}$ for $10 \mathrm{~min}$ and then cooled to room temperature at different rates: a, b $100{ }^{\circ} \mathrm{C} / \mathrm{s}$, c $20{ }^{\circ} \mathrm{C} / \mathrm{s}$, d $5{ }^{\circ} \mathrm{C} / \mathrm{s}$, e $1{ }^{\circ} \mathrm{C} / \mathrm{s}$

concentration in the liquid and favor the $\gamma$ matrix growth between them, forming the comb-like structure of fine $\gamma$ and $\gamma^{\prime}$. Once the comb-like structure in which the $\gamma$ and $\gamma^{\prime}$ distributed alternately is formed, they will grow into the liquids by the eutectic reaction of $\mathrm{L} \rightarrow\left(\gamma+\gamma^{\prime}\right)$ via diffusion. When the cooling rate is as high as $100{ }^{\circ} \mathrm{C} / \mathrm{s}$, the time is too short for the progress of the eutectic reaction via diffusion, and the $\left(\gamma+\gamma^{\prime}\right)$ growth ceases, leaving the crust- like structure of $\left(\gamma+\gamma^{\prime}\right)$ at the outer side of the liquid pool as shown in Fig. 5a, b.

Comparing the morphology of the $\left(\gamma+\gamma^{\prime}\right)$ developed under different cooling rates as shown in Fig. 5, it can be confirmed that the precipitates originate from the primary $\gamma$ dendrites, which forms a fine net-like structure of $\gamma$ and $\gamma^{\prime}$, and finally the $\gamma^{\prime}$ coarsens extensively. This is apparently contrary to the conclusion that the fine net-like part is 
Table 2 Composition of the fine lath-like $\eta$ phase and honeycomb-like $\gamma$ phase inside the liquid pools and the fine $\left(\gamma+\gamma^{\prime}\right)$ at the edge of the liquid pools in the sample cooled at $100{ }^{\circ} \mathrm{C} / \mathrm{s}$ (EDS results, wt $\%$ )

\begin{tabular}{lllllllll}
\hline Phase & $\mathrm{Al}$ & $\mathrm{Ti}$ & $\mathrm{Cr}$ & $\mathrm{Co}$ & $\mathrm{Ni}$ & $\mathrm{Mo}$ & $\mathrm{W}$ & $\mathrm{Zr}$ \\
\hline Lath-like $\eta$ & 2.19 & 15.05 & 5.49 & 14.30 & 57.72 & 1.56 & 1.43 \\
Honeycomb-like $\gamma$ & 2.23 & 12.63 & 9.62 & 14.97 & 51.57 & 2.94 & 2.20 \\
$\left(\gamma+\gamma^{\prime}\right)$ & 3.94 & 12.58 & 5.70 & 11.52 & 64.28 & 1.14 & 0.85 & - \\
\hline
\end{tabular}
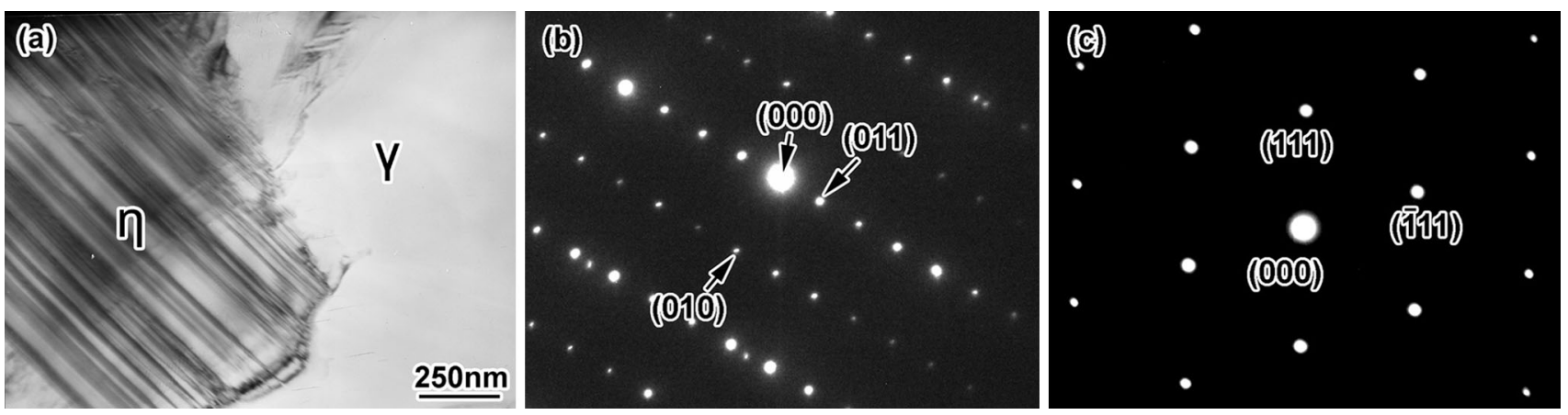

Fig. 6 TEM image and the corresponding selected area diffraction patterns of a lath-like $\eta$ phase and the $\gamma$ phase surrounding the $\eta$ phase in the sample cooled at $100{ }^{\circ} \mathrm{C} / \mathrm{s}$ : a morphologies of the $\eta$ phase and $\gamma$ phase, $\mathbf{b} \eta$ phase at [100] zone axis, $\mathbf{c} \gamma$ phase at [001] zone axis
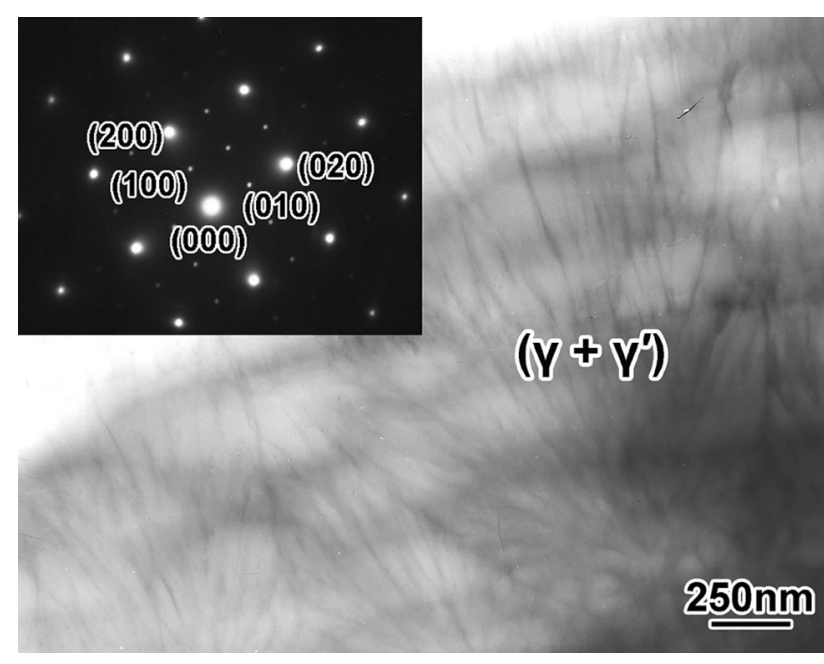

Fig. 7 TEM image of the fine $\left(\gamma+\gamma^{\prime}\right)$ in the sample cooled at $100{ }^{\circ} \mathrm{C} / \mathrm{s}$ and the corresponding selected area diffraction pattern at [001] zone axis

formed after the coarse cap-like part [8]. Because the final liquid is rich in $\mathrm{B}$ and $\mathrm{Zr}$, which is not dissolved in $\gamma$ and $\gamma^{\prime}$ as shown in Fig. 3 and Table 2, it is difficult for $\gamma$ and $\gamma^{\prime}$ to nucleate directly from the residual liquid, and the $\left(\gamma+\gamma^{\prime}\right)$ can only grow into lamellar structure as shown in Fig. 5d, e. The growth of $\gamma^{\prime}$ depletes $\mathrm{Al}$ and Ti nearby and the neighboring $\gamma^{\prime}$ naturally grow divergently, forming a fanlike shape of $\left(\gamma+\gamma^{\prime}\right)$ as shown in Fig. 5d, e. At the final stage of $\left(\gamma+\gamma^{\prime}\right)$ precipitation, the space between $\gamma^{\prime}$ phases become larger and it can only grow by coarsening due to the difficulty of nucleation.

Although the additions of $\mathrm{B}$ and $\mathrm{Zr}$ are at minor level, they have a noticeable effect on the final solidification of U720Li alloy. When cooled at $100{ }^{\circ} \mathrm{C} / \mathrm{s}$, the amount of $\left(\gamma+\gamma^{\prime}\right)$ is relatively less and that of the residual liquids is thus larger, the $\mathrm{B}$ and $\mathrm{Zr}$ concentrations in the residual liquids are not too high and the liquids are solidified into $\gamma$ solids with a chilled microstructure such as honeycomb as shown in Fig. 5a. Some lath-like $\eta$ phases are formed because they can absorb $\mathrm{Ti}$ and $\mathrm{Zr}$ in the liquids favoring the $\gamma$ phase precipitation. When the cooling rate is decreased to the level of $20{ }^{\circ} \mathrm{C} / \mathrm{s}$, the residual liquids are reduced noticeably by the $\left(\gamma+\gamma^{\prime}\right)$ growth, and the concentrations of $\mathrm{B}$ and $\mathrm{Zr}$ in the residual liquids are markedly increased with the progress of the solidification. As a result, the growth rate of the $\left(\gamma+\gamma^{\prime}\right)$ is reduced to very low level and $\gamma$ phase cannot precipitate directly from the residual liquids, and thus, the residual liquids are deeply cooled and the solidification is finished by the pseudo-eutectic reaction of $\mathrm{L} \rightarrow(\gamma+$ boride $)$ and $\mathrm{L} \rightarrow(\gamma+\eta)$, which absorbs B and $\mathrm{Zr}$. The pseudo-reaction enlarges the composition scope for the boride and $\eta$ phase formation and the amount of boride and $\eta$ phase is relatively large. When the cooling rate is lower than $5{ }^{\circ} \mathrm{C} / \mathrm{s}$, the growth of $\left(\gamma+\gamma^{\prime}\right)$ nearly consumes up the residual liquids, only a very low amount of liquids is left as shown in Fig. 5d. According to above discussion, the eutectic growth of $\left(\gamma+\gamma^{\prime}\right)$ is a diffusion dependent progress. When the 
cooling rate is lower than $1{ }^{\circ} \mathrm{C} / \mathrm{s}$, the growth of $\left(\gamma+\gamma^{\prime}\right)$ can absorb most of the residual liquids, and the boride and $\mathrm{Zr}$ bearing phase begin to precipitate and the solidification of the alloy is finished, forming the routinely observed as-cast microstructure as shown in Fig. 5e. At such a low cooling rate, the super cooling can be neglected and the boride and $\eta$ phase can only form at a quasi-equilibrium state when the concentration and temperature are fit for their precipitation, and its precipitation is largely lowered compared with that cooled at a higher rate, such as $20^{\circ} \mathrm{C} / \mathrm{s}$. As shown in Fig. 3, Ti is poor at the growth front of $\left(\gamma+\gamma^{\prime}\right)$. However, $\eta$ - $\mathrm{Ni}_{3} \mathrm{Ti}$ phase is observed occasionally at the front edge of the $\left(\gamma+\gamma^{\prime}\right)$. As shown in Table 1 and Fig. 3, the $\eta$ phase is mainly constituent by $\mathrm{Ni}$ and $\mathrm{Ti}$ and depleted in $\mathrm{Cr}$ and $\mathrm{Mo}$, while the borides are enriched in $\mathrm{Cr}$ and $\mathrm{Mo}$ and depleted in $\mathrm{Ni}$ and $\mathrm{Ti}$. So the compositions of the two phases are complemental and they were always precipitated together (Fig. 2b), which is consistent with Ref. [4]. Therefore, the precipitation of borides in front of the $\left(\gamma+\gamma^{\prime}\right)$ led to a high local concentration of $\mathrm{Ti}$ in the residue liquids near the borides and the precipitation of $\eta$ phase.

\section{Conclusions}

1. The $\left(\gamma+\gamma^{\prime}\right)$ precipitation is not a eutectic reaction completely as deemed routinely, and it begins with a peritectic reaction of $(\mathrm{L}+\gamma) \rightarrow \gamma^{\prime}$, and develops by eutectic reaction of $\mathrm{L} \rightarrow\left(\gamma+\gamma^{\prime}\right)$.

2. The course cap-like structure is formed at the final stage of the $\left(\gamma+\gamma^{\prime}\right)$ precipitation because the $\gamma^{\prime}$ is difficult to nucleate directly from the liquids.
3. The compositions of boride and $\eta$ phase are complementary, and they precipitate at the same place especially when the cooling rate is low enough.

\section{References}

[1] S.M. Seo, J.H. Lee, Y.S. Yoo, C.Y. Jo, H. Miyahara, K. Ogi, Metall. Mater. Trans. A 42, 3150 (2011)

[2] H. Monajati, A.K. Taheri, M. Jahazi, S. Yue, Metall. Mater. Trans. A 36, 895 (2005)

[3] J. Mao, K.M. Chang, W. Yang, K. Ray, S.P. Vaze, D.U. Ferrer, Metall. Mater. Trans. A 32, 2441 (2001)

[4] G.D. Zhao, L.X. Yu, F. Qi, F. Liu, W.R. Sun, Z.Q. Hu, Acta Metall. Sin. (Engl. Lett.) 29, 518 (2016)

[5] L. Chang, H. Jin, W. Sun, J. Alloys Compd. 653, 266 (2015)

[6] J. Zhang, R.F. Singer, Metall. Mater. Trans. A 35, 1337 (2004)

[7] K. Hilpert, D. Kobertz, V. Venugopal, M. Miller, H. Cerads, F.J. Bremer, H. Nickel, Z. Naturforsch. A 42, 1327 (1987)

[8] N. D’Souza, H.B. Dong, Scr. Mater. 56, 41 (2007)

[9] X.Y. Zhang, L. Liu, T.W. Huang, J. Zhang, H.Z. Fu, Rare Metal Mater. Eng. 42, 2547 (2013)

[10] L. Liu, T.W. Huang, J. Zhang, H.Z. Fu, Mater. Lett. 61, 227 (2007)

[11] B.C. Wilson, J.A. Hickman, G.E. Fuchs, JOM 55, 35 (2003)

[12] T.J. Garosshen, T.D. Tillman, G.P. McCarthy, Metall. Trans. A 18, 69 (1987)

[13] B.C. Yan, J. Zhang, L.H. Lou, Mater. Sci. Eng., A 474, 39 (2008)

[14] A.V. Shulga, J. Alloys Compd. 436, 155 (2007)

[15] G. Zhao, L. Yu, G. Yang, W. Zhang, W. Sun, J. Alloys Compd. 686, 194 (2016)

[16] S.M. Seo, I.S. Kim, J.H. Lee, C.Y. Jo, H. Miyahara, K. Ogi, Metall. Mater. Trans. A 38, 883 (2007)

[17] N. Warnken, D. Ma, M. Mathes, I. Steinbach, Mater. Sci. Eng., A 413, 267 (2005) 